KS the administration of adrenaline should be carefully evaluated as adrenaline, having vasoconstriction effects, can worsen the myocardial ischemia.

Conclusions It is our opinion that work suitability cannot be granted to beekeepers who developed KS with.

\section{OCCUPATIONAL CONTACT DERMATITIS}

EA Ozgur*, Y Demıral, AH Cımrın. Dokuz Eylül University Medical School, Occupational Medicine, Izmir, Turkey

\subsection{6/oemed-2018-ICOHabstracts. 147}

Introduction Dermatoses are a group of diseases that are common among occupational diseases. Occurrence is seen between $10 \%-40 \%$ and is the second most common occupational disease after muscular and skeletal system diseases. In this study, we aimed to evaluate the general characteristics of the occupational diseases evaluated by occupational dermatosis in our clinic about 3 years.

Methods A total of 23 patients who applied between 2014-2017 were evaluated retrospectively. A detailed business story was taken from the cases and clinical evaluation was done. Materials MSDS information was requested from the workplaces. Patch test was applied to the cases where contact dermatitis was suspected. Other dermatological diseases were excluded and evaluated as allergic and irritant contact dermatitis according to the patch test results. Statistical evaluations were performed using the PASW Statistics for Windows (SPSS Inc. Version 18.0, Released 2009, Chicago, USA) statistical package program.

Results When the demographic characteristics were examined, $21.74 \%$ of the cases were female and $78.26 \%$ were male. The initial area of the lesions was 52\%. Six of the cases were diagnosed with other dermatological diseases, 12 with allergic contact dermatitis and 4 with irritant contact The most common allergens were nickel sulphate $(73.3 \%)$, potassium dichromate (40\%) and tiuram (20\%). Time interval between onset of lesions and the date they first appeared (latent periods) according to the sectors is given in the tables.

Conclusion Occupational dermatoses refer to our clinic, constitute $3.7 \%$ of occupational disease-related cases and 5 th place among other occupational diseases. It was observed that the cases came from different sectors, mostly male and between 30-40 years old. Occupational history and patch test results are important for diagnosis. Since the latent period is variable, it is not very meaningful in predicting the occurrence of the disease when examined in terms of substance and sectoral distribution.

\section{AIRBORNE POLLEN SAMPLING AT TWO DIFFERENT HEIGHTS: VARIATION OF CONCENTRATIONS IN INDOOR AND OUTDOOR ENVIRONMENTS AND IMPLICATION FOR OCCUPATIONAL HEALTH}

${ }^{1} \mathrm{P}$ Capone, ${ }^{1} \mathrm{~L}$ Boccacci, ${ }^{1} \mathrm{~S}$ Di Renzi, ${ }^{1} \mathrm{R}$ Ferrante, ${ }^{2} \mathrm{MA}$ Brighetti, ${ }^{3} \mathrm{MC}$ Serra, ${ }^{1} \mathrm{R}$ Sisto, ${ }^{1}$ A Pelliccioni, ${ }^{2}$ A Travaglini, ${ }^{1} M C$ D'Ovidio*. 'National Workers' Compensation Authority (INAIL), Department of Occupational and Environmental Medicine, Epidemiology and Hygiene, Monte Porzio Catone (Rome), Italy; ${ }^{2}$ University of Rome 'Tor Vergata', Department of Biology, Rome, Italy; ${ }^{3}$ Research Unit for Oenology in Central Italy (CREA ENC), Velletri (Rome), Italy

10.1136/oemed-2018-ICOHabstracts. 148
Introduction Allergic respiratory diseases, especially rhinitis and asthma, is of relevant importance within emerging occupational diseases in the last decades. It is therefore fundamental monitoring airborne pollen concentrations for allergic disease prevention. Many factors are able to influence airborne pollen concentrations: meteorological parameters (air temperature, relative humidity, wind speed), seasonal variations, geographical location, human habits and activity. In this context, for research purposes, we have carried out samplings at two different heights to investigate variations of concentrations of several types of airborne pollen in indoor and outdoor environments according to standard methods of the UNI 11108/ 2004 and following.

Methods Airborne pollen grains have been collected using a volumetric sampler, Lanzoni VPPS 2000 type Hirst based on impact collection of atmospheric biological particles. Sampling have been performed in one room office using two samplers located to different heights of the suction nozzle (at $1,10 \mathrm{~m}$ and 0,6 m) during 2016-2017 and in outdoor environment (urban area) using two same samplers situated to two different level (at ground level in Trajan Forum and at $45 \mathrm{~m}$ on ground level on Calandrelli Tower) during 2002-2003. Monitoring stripes were cut and stained with glycerine jelly with fuchsine and then observed with optical microscope to $40 \mathrm{X}$.

Results We observed that pollen concentration are higher at low altitude in both indoor and outdoor samplers. Normally, the outdoor pollen concentration at low level is six or seven times higher than at high altitude, while the indoor pollen is about two time higher.

Conclusion The versatility of sampling at different heights is a very valuable tool to explain how many factors both environmental and personal influence space-time distribution and turbulence related to aerodynamics of these biological particles. The results suggest that pollen gradients at lower level is about five time greater than in indoor respect to outdoor sites.

\section{OCCUPATIONAL IMMEDIATE ALLERGIES TO CHEMICALS}

Eva Helaskoski*, Hille Suojalehto, Kristiina Aalto-Korte. Finnish Institute of Occupational Health, Helsinki, Finland

\subsection{6/oemed-2018-ICOHabstracts. 149}

Introduction Exposure to chemicals occurs in a wide range of professional fields. Chemicals typically induce delayed, cell-mediated sensitisation, but some chemical agents are able to induce immediate-type allergy. The mechanisms of immediate sensitisation to chemicals are still mainly unknown, but specific IgE seems to play a role, at least for some chemical groups. The aim of our study was to evaluate the diagnostic procedures of occupational immediate allergic diseases caused by chemicals and assess the feasibility of skin testing in the diagnostics.

Methods We retrospectively reviewed the patient files of the Finnish Institute of Occupational Health for the period of 1991-2011 to find patients diagnosed with immediate sensitisation to chemicals. We collected data on occupation, exposure, work-related symptoms, clinical and immunological test results, and occupational allergic diseases.

Results Positive skin prick tests (SPT) were noted for organic acid anhydrides, diisocyanates, persulfates, epoxy resin, chlorhexidine and aziridine. Amine hardeners and formaldehyde induced multiple small indifferent reactions. For several other 
groups of chemicals sporadic or no positive SPTs were noted. Occupational contact urticaria (CU) caused by chemicals was diagnosed in 41 patients during the study period, 21 of them caused by acid anhydrides. More than half of the CU patients (54\%) had a concomitant allergic airway disease.

Discussion SPTs provide a fast and safe complementary tool for diagnosing immediate allergic diseases to some chemical groups, but the results should be interpreted cautiously and related to symptoms and other clinical tests. Occupational CU caused by chemicals is often accompanied by occupational airway diseases caused by the same agent.

\section{PREVALENCE OF ALLERGY RELATED SKIN AND RESPIRATORY DISEASES AMONG HEALTHCARE WORKERS IN CROATIA}

Hana Knezevic. Student, Medical school, University of Zagreb, Zagreb, Croatia

10.1136/oemed-2018-ICOHabstracts. 150

Introduction Healthcare workers are exposed to wet-work and occupational hazards such as latex, cleaning products and various medication drugs which can potentially cause allergic or irritant dermatitis and work-related rhinitis and asthma. The aim of this research was to investigate the prevalence of health issues related to the skin and respiratory tract among healthcare workers in hospital.

Methods Subjects of the research were 1021 healthcare workers employed in four clinical hospitals in Zagreb, Croatia, who filled the Work Ability Index Questionnaire. Questions about current skin diseases (allergic or other rash, eczema) and respiratory diseases (chronic or recurrent infections of the respiratory tract, bronchial asthma) diagnosed by the physician were extracted and analysed.

Result Out of 1021 healthcare workers, there were 721 nurses (47 man; 674 women) and 300 physicians (134 man; 166 women). It was found that allergic dermatitis and/or eczema was present in 15\% (109/721) nurses and in 15\% (46/300) physicians. Prevalence of respiratory diseases among nurses was 26\% (187/721), and 28\% among physicians (85/300). Coexisting skin and respiratory tract symptoms were present in $8 \%(77 / 1021)$ healthcare workers.

Discussion In this study atopic disorders and eczema were present in a significant percentage of the workers, as well as inflammation of the respiratory tract and bronchial asthma, but it couldn't be verified that symptoms are related to latex or other hazards. Individuals with a history of atopic disorders are at increased risk of latex allergy. According to ALAA, the estimated prevalence of latex allergy in healthcare workers varies between $8 \%-17 \%$. Further research in healthcare with a focus on the use of gloves, job tasks, and prevocational exposure to latex is needed.

\section{OCCUPATIONAL HAND ECZEMA AMONG CEMENT WORKERS IN NEPAL}

${ }^{1} \mathrm{SK}$ Joshi*, ${ }^{2 S}$ Bhattarai. 'Department of Community Medicine, Kathmandu Medical College, Kathmandu, Nepal; ' 2 Department of Dermatology, Kathmandu Medical College, Kathmandu, Nepal Affiliation

10.1136/oemed-2018-ICOHabstracts.151
Introduction Occupational dermatitis among cement workers is a major occupational health concern and skin contact with cement has been associated with contact dermatitis, which ranges from cement burns to cumulative irritant contact dermatitis. The objective of this study was to investigate the prevalence and severity of occupational cement contact dermatitis amongst cement workers in Nepal which is the first of its kind.

Methods This was a cross sectional descriptive study conducted amongst the workers in construction sites and hardware shops within the Kathmandu valley. A structured questionnaire was used to collect the demographic data and work-related activities of those cement workers. A complete skin examination was conducted and skin manifestations were assessed by a dermatologist. The data collected was compiled and appropriate statistical tools were used to find out the significance of variables.

Result Out of the 377 workers screened 164 (43.50\%) had hand contact dermatitis. There were males 148 (90.2\%) and females16 (9.8\%) and the age ranged from 15-51 years (mean $27.41 \pm 7.68$ years). The duration of the disease ranged from 1-360 months (median36months $(\mathrm{IQR}=60)$. The most common site of lesion was palms $(62.8 \%)$ followed by tip of the fingers in $39.0 \%$ patients and the most common morphology of the lesion was erythema seen in $59.1 \%$ followed by scaling seen in $51.8 \%$ patients.

Discussion Contact and irritant hand eczema amongst cement workers in Nepal has a considerable morbidity. Identification of these workers with adequate treatment, test of the suspected allergens and counselling could further help the workers. This study helped us to assess the magnitude of the problem and since it is a cross sectional survey, further research can be planned to see the allergens amongst the persons suspicious of contact dermatitis amongst the cement workers.

\section{MINERALOGY AND TEXTURES OF ASBESTOS: THE ROLE OF SINGLE VS AGGLOMERATED FIBRES IN TOXICOLOGICAL EXPERIMENTS}

${ }^{1} \mathrm{G}$ lezzi, ${ }^{2} \mathrm{G}$ Della Ventura, ${ }^{3}$ Manuela Nazzari, ${ }^{4} \mathrm{~F}$ Bellatreccia, ${ }^{5} \mathrm{M}$ Di Gioacchino, ${ }^{5} \mathrm{C}$ Petrarca*. ${ }^{1}$ INGEO University G. d'Annunzio of Chieti-Pescara, Chieti, Italy; ${ }^{2}$ Istituto Nazionale di Geofisica e Vulcanologia (INGV), Roma, Italy; ${ }^{3}$ INFN LNF Frascati, Roma, Italy; ${ }^{4}$ University Roma Tre, Roma, Italy; ${ }^{5}$ DMSI University G. d'Annunzio of Chieti-Pescara, Chieti, Italy

\subsection{6/oemed-2018-ICOHabstracts. 152}

Introduction Exposition to asbestos may cause adverse health effects, but a clear relationship between mineralogy and texture of fibres versus toxicity is still lacking. Toxicological studies can be properly interpreted and compared only if quantitative features of fibres are determined.

Methods Amphibole fibres were characterised by XRPD, FTIR, SEM-EDS and EMP-WDS. Fibres deposited from solutions of $0.1,1,10,25,50,75$ and $100 \mathrm{mg} / \mathrm{L}$ were counted using SEM images. The single vs agglomerated fibres was assessed. The viability of human lymphocytes exposed to the fibres was investigated by MTT test.

Results Only crystals with definite stoichiometry are present. At 0.1 and $1 \mathrm{mg} / \mathrm{L}$ the fibres are well separated, whereas between 1 and $10 \mathrm{mg} / \mathrm{L}$ they start to agglomerate. In vitro tests performed on fibres deposited at the same concentrations show that the cytotoxic effect rate decreases for asbestos concentration $>10 \mathrm{mg} / \mathrm{L}$. 